\title{
İktisadı Yeniden Felsefeyle Buluşturmak: Amartya Sen'in Adam Smith Okuması
}

\author{
Adem Levent
}

\begin{abstract}
Öz: Adam Smith, piyasa ekonomisinin en önemli teorisyeni ve modern iktisadın kurucusu olarak bilinmektedir. Bununla birlikte Smith'in düşünceleri etrafında birbiriyle uyumlu olmayan bir literatür bulunmaktadır. Bu literatür içerisinde Smith, iktisatçıların politik tercihlerine bağlı olarak ideolojik bir tartışmanın nesnesi haline getirilmektedir. Amartya Sen'in Smith ile ilgili düşünceleri dikkat çekmektedir. Sen'e göre Smith'in düşünceleri, çağdaş iktisat teorisinde yanlış yorumlanmıştır. Bu yanlış yorumlama, insan davranışlarının rasyonalitesi, piyasa ekonomisi ve devletin ekonomideki rolü gibi birkaç tema üzerinden günümüzde devam etmektedir. Smith'in yazılarındaki iddialar kişisel çıkara dayalı olmaktan daha çok sempati ve genel davranış kurallarına yöneliktir. Düzenleyici piyasalarda devletin rolü, Smith'in analizinde bulunmaktadır. Sen'e göre Smith'in düşüncelerinde, hoş görülü bir toplumun nasıl kurulacağının ve adalet ideasının nasıl gerçekleşeceğinin ipuçları da mevcuttur. Sen'in Smith okumasının biri disipliner diğeri de politik olmak üzere iki iması bulunmaktadır. Smith'e dayanılarak geliştirilen disipliner ima, Sen'in iktisat disiplinini dar bir çerçevenin dışında okuma ve geliştirme isteğidir. Politik ima ise iktisadi liberalizme yönelik örtük bir eleştiridir. Bu çalışmada Adam Smith'in Amartya Sen üzerindeki düşünsel etkisi ele alınmıştır. Bu etki, gelişen ticari toplumun ve iktisat disiplininin felsefi temelli kavranışına fırsat sunmaktadir.
\end{abstract}

Anahtar kelimeler: Adam Smith, Amartya Sen, Kişisel çıkar, İhtiyatlı davranış, Sosyal adalet.

\begin{abstract}
Adam Smith is known as the most important theorist of the market economy and the founder of modern economics. However, there is a literature around Smith's thoughts which are not compatible with each other. In this literature, Smith is brought into an object of ideological debate depending on the preferences of the political economists. Amartya Sen's thought about Smith is remarkable. According to Sen, the thought of Smith is misinterpreted in contemporary economic theory. This misinterpretation continues today through several themes such as rationality of human behavior, market economy and the role of state in the economy. The claims in Smith's writing is not based on self-interest, but is addressed to sympathy and general rules of behavior. The role of state in regulating market is presented in Smith's analysis. According to Sen, how to establish a tolerant society and the tips of how to take place the idea of justice are also available in Smith's thoughts. Sen's reading of Smith has two connotations: one of them is discipliner and the other one is politics. The discipliner connotation which is developed based on Smith is Sen's reading and enhancement requests of economics discipline outside a narrow framework. The political connotation is implicit criticism of economic liberalism. In this study, the ideational influence of Adam Smith on Amartya Sen is examined. The effect gives an opportunity to understand the thriving commercial community and philosophical base of economics discipline.
\end{abstract}

Keywords: Adam Smith, Amartya Sen, Self-interest, Prudence, Social justice.

(C) İlmi Etüdler Derneği

DOI: 10.12658/human.society.7.13.M0187

İnsan \& Toplum, 7(1), 2017, 117-137.

insanvetoplum.org 


\section{Giriş}

Adam Smith, piyasa ekonomisinin en önemli teorisyeni ve modern iktisadın kurucusu olarak bilinmektedir. Bununla birlikte son zamanlarda Smith'in düşünceleri, bazı sosyal demokrat akademisyenlerin de ilgi alanına girmekte ve sosyal demokrat yaklaşımların önemli düşünsel dayanaklarından biri olarak ele alınmaktadır (Smith, 2013a, s. 784). Bu şekilde Smith, sadece modern iktisadın kurucusu olarak kalmamakta, aynı zamanda liberal ve Marksist ideolojilere mensup araştırmacıların yaklaşımlarına da konu olmaktadır. Bu yaklaşımlar iktisatçıların piyasa ekonomisi ile ilgili farklı düşünceleri benimsemiş olmalarından kaynaklanmaktadır. Böylece Smith, iktisatçıların politik tercihlerine bağlı olarak ideolojik bir tartışmanın nesnesi haline getirilmektedir. İktisat düşüncesinin kendi içinde gelişen Adam Smith literatürü hem çok çeşitli hem de birbiriyle ihtilaflı bir yekûn tutmaktadır. Bu literatürün odağındaki Smith, disiplinin "kurucu" figürü olmanın yanı sıra, disiplinin sonraki seyrine ilişkin tercihlere göre de farklı yorumlara konu olmaktadır (Yılmaz, 2010, s. 65).

Bazı yorumlara göre Smith, kişisel çıkarın maksimizasyonuna dayalı davranışı, kişisel çıkar ve toplumsal yarar arasındaki uyumu, liberal toplumla ilgili sistematik bir dünya görüşünü ve doğal özgürlük sistemini savunmaktadır (Stigler, 1971, s. 265; Hutchison, 1994, s. 8; Skousen, 2003, s. 24; Schumpeter, 1986, s. 179). Baz1 yorumlara göre ise Smith, kesinlikle liberal bir düşünür değildir. Doktriner bir laissez faire savunusu yapmamaktadır. Smith için piyasa mekanizması ancak uygun yasal ve kurumsal bir çerçeveyle geçerli olmaktadır. Hatta anti-Lockcu devlet görüşünü benimsemektedir (Khalil, 2002, s. 665; Blaug, 1999: s. 62; Viner, 1927, s. 231).

Smith etrafında artarak devam eden ve birbiriyle uyumlu olmayan bu literatür, 20. yüzyılın politik bağlamı etrafında, onun farklı anlaşılmasına yol açmıştır. Her kesim kendine göre bir Smith profili çizmiştir. Ortodoks iktisat teorisine de Smith, bu bağlam çerçevesinde taşınmaktadır. 20. yüzyılın en yaygın Smith yorumu olan liberal anlayışa göre Smith, kişisel çıkarın en önemli kuramcısıdır.

Amartya Sen ise (1986; 2003; 2004; 2009a; 2009b; 2010; 2011; 2013) yeni bir Adam Smith okumasıyla dikkat çekmektedir. Sen'e göre insan davranışlarının yalnızca kişisel çıkara dayalı yaklaşımını Smith'e dayandırmak hatalıdır. Smith'in yazılarında kişisel çıkara dayalı davranıştan daha çok sempati ve genel davranı̧̧ kuralları merkezî bir yer tutmaktadır. Sen'in Smith'i yorumlamasındaki temel iddiası, Adam Smith'in analizinde, ana akım refah iktisadının ve insan davranışlarının dar modellemesinin eleştirisinin bulunmasıdır. Refah iktisadının ve standart iktisattaki insan davranışları sorunlarını çözecek sosyal kurumlar ve genel davranış kuralları, Smith'in yaklaşımında mevcuttur. Sen, Smith'i kendi görüşleriyle ilişkilendir- 
mekte, insan davranışı ve iktisat disiplinine alternatif teorik yaklaşımını Smith'e atıf yaparak geliştirmektedir (Eiffe, 2008, s. 1).

Sen, kişisel çıkara dayalı davranışların insan yaşamındaki yeri, devletin ekonomideki rolü, sosyal adalet, yoksulluk ve kalkınma gibi belli başlı temalar üzerinden Smith'in düşüncelerini yeniden değerlendirmektedir. Sen'in Smith'le ilgili düşünceleri, daha çok Smith'in Ahlaki Duygular Kuramı (The Theory of Moral Sentiments) adlı eserine dayanmakta ve standart Smith yorumlarından farklılaşmaktadır. Sen'e göre Smith'in Ulusların Zenginliği (The Wealth of Nations) adlı eseri iktisat literatüründe tanınmakla beraber genellikle yanlış yorumlanmaktadır. Ahlaki Duygular Kuramı adlı eseri ise iktisat literatüründe hem pek tanınmamakta hem de ihmal edilmektedir. İhmal edilen konular Smith'in katkılarının mevcut teoriye acil bir şekilde eklenmesi gerektiğini göstermektedir. İhmal edilen konular arasında çağdaş dünya sorunlarıyla ilgili birçok düşünce bulunmaktadır (Sen, 2013, s. 581). Bu bağlamda Sen, geliştirdiği yapabilirlik yaklaşımında, insan davranışlarının salt kişisel çıkara indirgenemeyeceği, değerlerin ve kurumların saf dışı bırakıldığı pür piyasa ekonomisinin toplumsal fayda sağlayamayacağı, kalkınmada devletin rolünün göz ardı edilemeyeceği gibi Smith'in çalışmalarında yer alan ancak görmezden gelinen görüşleri gündeme getirmiştir (Boz, 2012, s. 75).

Bu çalışma, iktisat disiplinin henüz tam olarak formelleşmediği bir dönemde Smith'le başlayan politik iktisat tartışmalarının günümüz iktisadi sorunlarına nasıl tahvil edileceğini, Sen'in çalışmalarına dayandırarak yeni bir Smith okumasının gerekliliğiyle açıklama iddiasındadır. Bu amaçla öncelikle Smith'in Sen üzerindeki düşünsel etkisi ele alınacak, daha sonra bu düşünceler bağlamında çağdaş ekonomik ve politik sorunlar Smith ile ilişkilendirilecektir. Son olarak da Sen'in Smith yorumuyla doğrudan ilişkili olan Adam Smith Sorunu irdelenecektir.

\section{Adam Smith, Kişisel Çıkar ve İhtiyatı Davranış}

Sen'e göre Smith'in düşünceleri, çağdaş iktisat teorisinde yanlış yorumlanmıştır. Bu yanlış yorumlama, insan davranışlarının rasyonalitesi, piyasa ekonomisi ve devletin ekonomideki rolü gibi birkaç tema üzerinden günümüzde de devam etmekte$\operatorname{dir}$ (Sen, 2011).

İnsan davranışlarının kişisel çıkara dayalı açıklanması, Smith'in yanlış yorumlandığı temaların başında gelmektedir. Sen'e göre yerleşik iktisat teorisinde davranışların rasyonalitesini tanımlamanın iki ana metodolojisi bulunmaktadır. Birinci metodoloji, rasyonaliteyi seçimlerin iç tutarlılığı olarak görmektedir. Gerçek hayatta ortaya çıkan seçimler kümesi, herhangi bir ikili bağıntı temelinde, maksimizasyonun bir sonucu olarak açıklanabilir. Rasyonel seçim, insanın gerçekleştirmeye ça- 
lıştığı sonuç ile bunun yapılış tarzı arasında asgari bir uygunluk bağını koşul olarak almak zorundadır. İkinci metodoloji ise rasyonaliteyi kişisel çıkarın maksimizasyonu ile özdeşleştirmektedir. Bu doğrultuda seçimler kişisel çıkarın artırılmasına yönelik olmalıdır. Rasyonalitenin ikinci metodolojisi, yani kişisel çıkarın maksimizasyonu, bir insanın yaptığı seçimler ile onun kişisel çıkarı arasında dışsal bir uygunluk koşulu üzerine yükselmektedir. Tarihsel kökeni bakımından rasyonalitenin kişisel çıkar temelindeki yorumu uzun bir geçmişe sahiptir. Bir kaç yüzyıldır iktisat teorisinin ana akımının temel özelliklerinden biri olagelmiştir. Rasyonalitenin bu metodolojisi, genelde Adam Smith'e dayandırılmaktadır (Sen, 2003, s. 22-24).

Sen'e göre kişisel çıkara dayalı davranışın her durumda geçerli olduğu ve etkinlik sağladığı görüşünden hep "Smithyen" görüş olarak söz edilmesine rağmen, Smith'in bu önermelere inandığ konusunda yeterli kanıt yoktur. Smith'in Ahlaki Duygular Kuramı adlı kitabında açıkladığı gibi, ihtiyatlı davranış, "akıl ve kavrayış" özelliği ile "kendine hâkim olma" özelliğinin birliğidir. Smith’in Stoacı felsefeden aldığı "kendine hâkim olma" kavramı, hiçbir biçimde "kişisel çıkar"la özdeş değildir.

Smith'in "ahlaki duygular" konusundaki anlayışının Stoacı kökeni, iyi davranış anlayışında hem sempatinin hem de öz disiplinin neden o kadar önemli bir rol oynadığını açıklığa kavuşturmaktadır. Stoacılara göre insan kendi çıkarını büyük topluluğun çıkarı uğruna feda edilmesine her an istekli olmalıdır. Her ne kadar ihtiyatlı davranma kişisel çıar maksimizasyonunun çok ötesinde bir şey olsa da, Smith bunu genel olarak bütün erdemler arasında bireye en yararlı olan davranı̧s gibi görmüştür. Buna karşılık insan olma, adalet, cömertlik ve kamusal bir ruh halini başkalarına en çok yararlı olan nitelikler olarak saymıştır (Sen, 2003, s. 28-30).

Smith, "kendine hâkim olma" ve "sempati" kavramlarına sıkı sıkıya bağlıdır. Fakat bu gerçek, kişisel çıkar ve bunun faydaları konusunda "Smithyen" olarak bilinen birçok iktisatçının yazılarında gözden kaybolmuştur. Elbette, Smith, eylemlerimizin birçoğunun gerçekten kişisel çıkar tarafından yönlendirildiğini ve bunların bir bölümünün iyi sonuçlar doğurduğunu ifade etmektedir. Ancak Sen'e göre günümüz Smithyenlerinin yaptıkları: "Yemeğimizi, kasabın, biracının ya da firıncının iyilikseverliğinden değil, kendi çıkarlarını kollamalarından bekleriz. Onların insanlığına değil, ben sevgisine hitap ederiz. Hiçbir zaman kendi ihtiyacımızı ağzımıza almaz, onların kendi faydasindan söz ederiz (Smith, 2013b, s. 16)." şeklindeki ünlü alıntı, yanlış yorumlanmaktadır. Çünkü Sen'e göre Smith'in yapmak istediği şey, yorumlayıcılarından çok farklıdır. Zaten alıntılanan metnin içinde yer aldığı bölümün konusu da iş bölümüdür. Dolayısıyla metin iş bölümünün neden ve nasıl işlediğini anlatmak içindir. Smith için iş bölümü, evrensel refahın temel kaynağıdır. Smith'in karşılıklı olarak her iki tarafa da avantaj sağlayan ticari işlemlerin çok yaygın olduğunu kaydetmiş 
olması, hiç de yalnızca ben sevgisinin ya da daha geniş bir kavram olarak ihtiyatlı davranmanın iyi bir toplum için yeterli olacağını düşündüğü anlamına gelmez. Gerçekte Smith tam tersini iddia etmektedir. Ekonomik refahı sadece insan davranışına dayandırmamaktadır. Smith hiçbir çalışmasında kişisel çıkara genel olarak öteki faaliyetlerden üstün bir rol atfetmemektedir (Sen, 1986, s. 31-34; Rothschild ve Sen, 2006, s. 321, 357-358).

Sen'e göre Smith'in analizinin yanlış yorumlanması, 20. yüzyıl ekonomisinde zirve yapmıştır. Smith'i kişisel çıkara dayalı davranışların teorisyeni bağlamında yanlış yorumlayanların başında George Stigler gelmektedir. Stigler'e göre "kişisel çıkar, insanların çoğunu domine etmektedir ve bu düşünce Smithyen hatta gelişmektedir." (Stigler, 1971, s. 265). Stigler bu konuda yalnız değildir ve çoğu iktisatçı bu yaklaşımı benimsemektedir. 20. yüzyılda iktisatçıların geliştirdiği bu yaklaşım, "rasyonel seçim teorisi" olarak adlandırılmaktadır. Rasyonel seçim teorisindeki rasyonalite, entelektüel olarak, insanların yalnızca kendi kişisel çıkarını takip etmeleri olarak tanımlanmaktadır. Bu teoriye göre başkası için bir şey yaptığında, bundan bir şeyler elde ettiğin müddetçe bu davranış rasyonel olabilir. Başka türlü rasyonel bir davranış düşünülemez. Modern ekonomide takip edilen bu varsayım, iktisat ve hukuktaki bütün rasyonel seçim uzmanları ve politikacıları tarafından komşu disiplinlere de ihraç edilmektedir. Bu durumun yaygınlaşması "metodolojik emperyalizm"1 olarak bilinmektedir. Sen'e göre insan davranışlarının bu dar tanımında Smith'in Ahlaki Duygular Kuramı'nda yer verdiği “cömertlik, sosyal yükümlülük ve yardımseverlik" gibi makul erdemlere yer yoktur (Sen, 2011, s. 263). Bundan dolayı Sen, Shakespeare'e atıfla Smith için şu tespiti yapar: "Bazı insanlar basit doğarlar ve bazıları basitlik elde ederler. Açıktır ki, Adam Smith zorla basitleştirilmiştir.” (Sen, 1986, s. 28).

İnsan davranışlarının kişisel çıkara dayalı açıklaması rasyonalite olarak görülse de, aslında insanlar gerçek hayatta tamamen rasyonel (kişisel çıkara dayalı) davranmamaktadırlar. İnsan davranışlarını yönlendiren başka motivasyonlar da bulunmaktadır. Kuşkusuz kişisel çıkar, insanın sahip olduğu çeşitli motivasyonlar arasında en önemlilerinden biridir. Bu reddedilemez. Smith de haklı olarak bunu görmüştür. Fakat bununla birlikte Smith, ihtiyat kavramını da insan davranışlarının merkezine yerleştirmiştir (Sen, 1977, s. 336; Klamer, 1989, s. 142). nişletmek veya iktisadi olanı piyasa dışı ilişkileri de kapsayacak biçimde yeniden tanımlamaktır (Fine ve Milonakis, 2014, s. 73). Başka bir deyişle iktisadın komşu disiplinlere (siyaset bilimi ve sosyolojiye) yöntem ihraç etmesidir. Siyaset bilimi ve sosyoloji gibi diğer sosyal bilimlerin iktisat tarafından sömürgeleştirilmesi olarak da tanımlanmaktadır. Daha ayrıntılı bir tartışma için bkz. Lazear (2000, s. 103), Hirshleifer (1985). 
Kişisel çıkara dayalı davranışı savunanların Smith'ten almaya çalıştıkları destek, yazarın çalışmaları daha geniş bir açıdan ve yansız olarak incelendiğinde temelsiz kalacaktır. Modern dönemde Smith'in insan davranışları hakkındaki geniş bakış açısının daraltılması, çağdaş iktisat teorisinin en temel zaaflarından biridir (Sen, 2003, s. 33).

Sen'e göre Smith'in yanlış yorumlandiğı diğer temalar, piyasa ekonomisi ve devletin ekonomideki rolüdür. Sen'e göre yirminci yüzyılda Smith'e dayandırılarak oluşturulan piyasa ekonomisinin üç bileşeni bulunmaktadır. Birincisi, piyasa ekonomisinin kendi kendini düzenleyici doğasıdır. İkincisi, rasyonel davranışın temeli olarak kâr motivasyonunun görülmesidir. Sonuncusu ise kişisel çıkarın sosyal olarak üretici davranış yeterliliği sunmasıdır. Fakat Sen'e göre piyasa ekonomisinin üç özelliğini Smith'te bulmak zordur. Çünkü Smith, asla kapitalizm kavramını kullanmamıştır. Piyasa ekonomisinin kendi kendine yeterli olduğuna inanmamıştır. Elbette Ulusların Zenginliği’nde piyasa ekonomisinin dinamizmi ve yararlılı̆̆ını göstermiştir. Smith, bunu serbest ticaret ve uzmanlaşma bağlamında dile getirmiştir. Smith için piyasa süreci ve kâr motivasyonunun pozitif yönleri olduğu kadar negatif yönleri de vardır (Sen, 2011, s. 259; Sen, 2013, s. 583).

Başka bir deyişle düzenleyici piyasalarda devletin rolü, Smith'in analizinde çok fazla yer tutmaktadır. Smith, politik ekonomiyi iki önemli konunun sürdürülmesi olarak görmektedir: Birincisi, yeterli gelir sağlama veya halkın geçiminin sağlanmasıdır. İkincisi, kamu hizmetleri için devletin yeterli gelir elde etmesidir. Smith, serbest eğitim ve sağlık gibi kamu hizmetlerinin sağlanması için devletin rolünün belli bir oranda olması gerektiğine inanmaktadır.

Smith'in ekonomik analizinin yaygın bir biçimde ve vahim sonuçlar doğuracak tarzda yanlış yorumlanmış olduğu alanlardan biri de kıtllk veya açlık konusudur. Smith, her ne kadar genellikle kitlığın sorumlusu olarak tüccar kesimini gösterse de; aslında bu duruma onların yol açmadığını, kıtlığın "gerçek bir yokluktan" doğduğunu ileri sürmektedir. Smith, ticaretin engellenmesine veya kısıtlanmasına karşıdır. Ama bu, onun, kamunun yoksullara yardım etmesine karşı olduğu anlamına gelmemektedir. Smith, Malthus gibi Yoksullar Yasalarını reddetmemiştir. Smith, bu yasaların reforma ihtiyacı olduğunu düşünmüştür. Özellikle bu yasalardan yararlanacak olanları etkileyen kısıtlayıcı kuralların cezalandırıcı yönünün olmasından ziyade yasaların daha da serbestleşmesini savunmuştur. Smith'in kamu politikası yaklaşımında, yoksulların ihtiyaçlarına destek olmak amacıyla müdahaleyi dışlayacak hiç bir şey yoktur. Kitlığın nedeni olarak işsizlik ve düşük reel ücretlere işaret etmesi farklı türden kamu politikalarının mümkün olduğunu düşündürmektedir (Sen, 2011, s. 261-262; Sen, 2003, s. 31). 
Smith'in çağdaş iktisat teorisinde vülgarize edildiğine dair, Sen'in yaklaşımının dışında, göze çarpan başka çalışmalar da bulunmaktadır. Karl Polanyi ve Giovanni Arrighi de Sen'in yaklaşımılla benzer tespitlerde bulunmaktadır. Polanyi'ye göre Smith, maddi zenginliği ayrı bir çalışma alanı olarak ele almış, bunu büyük bir gerçeklik duygusuyla başarmış olması, onu yeni bir bilimin, iktisadın kurucusu yapmıştır. Bütün bunlara karşın, onun için zenginlik toplumun, yalnızca bir yönüdür; zenginlik, tarihte varoluşlarını sürdürebilmek için çabalayan ulusların bir parçasıdır ve onlardan ayrılamaz. Bu görüşe göre ulusların zenginliğini belirleyen koşulların bir bölümü bir bütün olarak ülkenin gelişen, durağan veya gerileyen konumundan; diğer bölümü ise güvenliğin taşıdığ önemden ve güç dengesine bağl1 ihtiyaçlardan kaynaklanmaktadır. Başka bir bölümü de hükümet politikasının şehirlere veya köylere, tarıma veya sanayiye tanıdığı önceliklere göre bu politika tarafindan belirlenmektedir. Nihayetinde Polanyi'ye göre Smith, zenginlik sorununun ancak belirli bir siyasal çerçeve içinde ortaya konulabileceğine inanmaktadır. Çalışmasında kapitalistlerin ekonomik çıkarlarının toplum yasalarını belirlediğini ima eden hiçbir şey yoktur. Smith, ulusların zenginliğini fiziksel ve ahlaki yönleriyle ulusal yaşama bağlı olarak ele almak istemektedir (Polanyi, 2000, s. 168-169).

Arrighi'ye göre de Smith, ne "kendi kendini düzenleyen" piyasaların ne de kapitalist gelişmenin savunucusu ve kuramcısıdır. Smith'in bir egemenlik gereci olarak piyasa kuramı, küreselleşen Avrupa devlet sistemine eklemlenmeden önceki Çin gibi, kapitalist olmayan pazar ekonomilerinin anlaşılması açısından özellikle geçerlidir. Ayrıca Smith, büyük iktisatçılar arasında belki de kendisine en çok atıfta bulunulan buna karşın en az okunan kişidir. Smith'in siyasal iktisadının amacı, devlete kamusal hizmetler için yeterli bir gelir tedarik etmek olduğu kadar, halka bol miktarda geçim aracı sağlamak, daha doğrusu onları kendi geçimlerini kendilerinin sağlamasına muktedir kılmaktır. Dolayısıyla 19. yüzyılın tipik liberal görüşü olarak minimalist hükümetler ile 20. yüzyıl sonlarında Washington Mutabakatı tarafından savunulan "şok terapilerinin" tedavi edici gücüne duyulan inanç, Smith'e bütünüyle yabancıdır (Arrighi, 2009, s. 55-57).

\section{Adam Smith ve Çağdaş Politik Düşünce}

Sen'e göre Smith'in düşüncesi, 2008 krizini açılamada ve yaşadığımız güncel iktisadi ve politik sorunları anlamada önemlidir. Onun iddiasına göre Smith, bir yandan krize öneri sunarken diğer yandan hoş görülü bir toplumun nasıl kurulacağ1nın ve adalet ideasının nasıl gerçekleşeceğinin ipuçlarını vermektedir. Bu da güncel olarak sosyal adalet konusuna girmektedir (Sen, 2009b). 
Sen'e göre sosyal adalet düşüncesinin uzun bir geçmişinin bulunmasına rağmen bu düşüncenin sistematik bir şekilde ele alınışı Aydınlanma döneminde olmuştur. Aydınlanma düşüncesi, 18. ve 19. yüzyıldan sonra değişen politik, sosyal ve ekonomik çevreyle ilgilidir. Bu tarihten itibaren sosyal adalet düşüncesi iki temel yaklaşımla ele alınmaktadır. Birinci yaklaşım, 17. yüzyılda Thomas Hobbes'un çalışmalarıyla başlamış, John Locke, Jean-Jacques Rousseau ve Immanuel Kant'ın düşünceleriyle devam etmiş olan sosyal sözleşme geleneğidir; bu anlayış toplum için kurumsal düzenleme önermektedir. Bu yaklaşım, "aşkın kurumsalcılık” (transcendental institutionalism) olarak adlandırılmaktadır. Bu yaklaşımın dikkate değer iki özelliği bulunmaktadır. Birincisi, adalet ve adaletsizliği karşılaştırmaktan ziyade kusursuz bir adalet tanımlaması yapmaya yönelik çabalarıdır. Bu yaklaşım, toplumlar arası karşılaştırmaya yoğunlaşmamaktadır. Sadece adaletin doğasını tanımlamaya çalışmaktadır. Bu yaklaşımın ikincisi ise, kurumsal düzenlemelere ağırlık vermesidir. Bu yaklaşımda toplumların aktüel sorunlarına değinilmemektedir. Toplumun doğası, kurumsal olduğu kadar kurumsal olmayan özelliklerle tanımlanmaya çalışılır.

Sosyal sözleşme geleneğinden ayrı olarak sosyal adalet düşüncesinin ele alındığ1 ikinci yaklaşım ise, sosyal gerçekleşme geleneğidir. Bu gelenek karşılaştırmalı bir yaklaşım sunmaktadır. Aktüel kurumlar, aktüel davranışlar ve diğer aktüel etkiler karşılaştırmalı bir şekilde ele alınarak sosyal adalet gerçekleştirilmeye çalışılır. Sen'e göre, bu geleneğin birçok Aydınlanma düşünürü tarafından temsil edilmesine rağmen en güçlü temsilcisi Adam Smith'tir. Smith'ten başka Marquis de Condorcet, Jeremy Bentham, Mary Wollstonecraft, Karl Marx ve John Stuart Mill bu geleneğe dâhil edilebilecek diğer yenilikçi düşünürlerdir. Bu yazarların aralarında farklar bulunmasına karşın hepsinin ortak noktası, adaletin nasıl gerçekleştirilebileceğidir. $\mathrm{Bu}$ yazarlar, aşkın kurumsalcı gelenek gibi sadece adaleti mükemmel bir şekilde tanımlamaya kalkışmazlar. Onların temel amacı, adaletin gerçekleşmesi için dünya üzerindeki adaletsizlikleri, köleliği, yoksulluğu, sömürüyü ve kadın istismarını kaldirmaktır (Sen, 2010, s. 57-58; Sen, 2013, s. 588).

Bu iki yaklaşım arasındaki güncel tartışma, Sen'e göre Smith'in düşünceleri yardımıyla daha iyi bir şekilde anlaşılacaktır. Aynı zamanda Smith'in düşüncelerinin analizi hem sosyal adalet geleneklerinin anlaşılmasına hem de günümüzün güncel politik, ekonomik ve felsefi sorunlarını çözüme kavuşturma açısından önem arz etmektedir.

İlk yaklaşım olan aşkın kurumsalcılık, bugünün ana politik felsefe geleneğidir. Günümüzde bu geleneğin en güçlü ve dikkate değer temsilcisi öncü politik filozof John Rawls'tır. Rawls, Bir Adalet Teorisi (A Theory of Justice) adlı eserinde "adalet 
ilkelerini”, kusursuz adil kurumları tanımlamak için tasarlamaktadır. ${ }^{2}$ Bu geleneğin diğer çağdaş temsilcileri, Ronald Dworkin, David Gauthier ve Robert Nozick'tir. Bu yazarlar farklı biçimlerde ifade etseler de hepsinin ortak amacı, toplumu adaletli yapıya kavuşturacak kuralları ve kurumları tanımlamak ve belirlemektir.

Bütün bu gelenek Smithyen olmayan bir yaklaşımı ifade etmektedir. Smith'in üzerinde durduğu düşünce, kurumsal düzenlemeler ve kurumlardan daha ziyade adaletin aktüel gerçekleştirilmesine dairdir. Bu bağlamda Smith'in yaklaşımında "Adalet nasıl geliştirilebilir?” sorusuna cevap aranırken, Rawls'ın yaklaşımında "Adil kurumları nasıl kusursuz bir şekilde tanımlayabiliriz?" sorusuna cevap aranmaktadır. Dolayısıyla iki sosyal adalet geleneği arasında köklü bir ayrım bulunmaktadır. Smith, toplumun kendi kendini gerçekleştirmesine yoğunlaşmaktadır. Smith'in bu düşünceleri çağdaş adalet teorisini radikal bir şekilde değiştirecektir (Sen, 2009a, s. 5-7; Sen, 2010, s. 59).

Ayrıca Smith, geliştirdiği "tarafsız gözlemci” aygıtıyla sosyal adaletin gerçekleşmesine zemin hazırlayarak sosyal sözleşmeci gelenekten ayrılmaktadır. Rawls, "hakkaniyet olarak adalet" (justice as fairness) teorisinde "düşünümsel denge" (reflective equilibirim) ile toplumdaki insanları "orijinal pozisyona" yerleştirmektedir. Smith ise tarafsız gözlemci aygıtını, “açık tarafsızlık”a dayandırarak Rawls'ın "kapalı tarafsızlığından" ayrılır. Açık tarafsızlık ilkesi ile Smith, Kant'ın ahlaki görüşlerine yaklaşmaktadır. Rawls'ın sosyal sözleşme ile insanları sınırlandırmak istemesine karşın Smith, tarafsız gözlemci ile yakın veya uzak görüşleri birleştirmek istemektedir (Sen, 2013, s. 589).

Sen'e göre Smith'in ve sosyal sözleşmeci geleneğin sosyal adalet yaklaşımlarının en iyi karşılaştırılma alanı, 1770 yılında İngilizlerin yönetimindeki Hindistan'da baş gösteren kıtlıktır. Sosyal sözleşmeci geleneğe dayalı ve yeterli kaynakları olan İngiltere, Hindistan'ın yaşadığı kıtlık sorununa çözüm sunmamaktadır. Bu da İn-

2 Rawls, Bir Adalet Teorisi adlı eserinin amacinın, adalet kavramını, Locke, Rousseau ve Kant'ta bulunan sosyal sözleşme geleneğine dayanarak genelleştirip daha yüksek bir soyutluluk aşamasına taşımak olduğunu belirtmiştir (Rawls, 2005, s. 11). Yine Rawls, Bir Adalet Teorisi eserinden sonra kaleme aldığ1 Siyasal Liberalizm adlı eserinin temel amaçlarından birisinin, hakkaniyet olarak adaletin yerini bulduğu iyi düzenlenmiş bir toplumda, Bir Adalet Teorisi'nde açıklandığı üzere, makul çoğulculuğun varlığı ve siyasal adalet anlayışının egemenliği durumunda nasıl anlaşılması gerektiğini açığa kavuşturmak olduğunu belirtmiştir (Rawls, 2007, s. 23). Görüldügü gibi Rawls'ın yaklaşımının üstünlüğü sistematikliğidir. Rawls her ne kadar faydacı geleneği eleştirerek adalet teorisinin geliştirmek istese de aslında yaptığı politik bir teorizasyondan daha çok iktisattır. Politik felsefeyle ilgili çok sayıda eser, iktisat biliminden kaynaklan ve Amerika'da toplumsal tercih ya da rasyonel seçim kuramı olarak adlandırılan yöntemlerden esinlenmektedir. Rawls'in Adalet Teorisi rasyonel tercih kuramının belki de en önemli bölümüdür (Meda, 2012, s. 257). 
giltere'nin Hindistan için yeterli sosyal adaleti gerçekleştirmediğine işarettir. Sen'e göre benzer sorunlar bugün de canlı bir şekilde devam etmektedir. Amerikan ekonomisi sadece Amerikan vatandaşlarının yaşam sorunlarıyla ilgilenmemeli, dünyanın geri kalan insanlarının sorunlarıyla da mücadele etmelidir. G-20 buluşmaları bunun bir adımıdır. Aynı şekilde ülkeden ülkeye ve kıtadan kıtaya yayılan AIDS ve diğer salgın hastalıklarla da tüm dünya birlikte mücadele etmelidir. Bu adımlar Rawls'in adalet teorisinden ziyade Smith'in adalet anlayışına daha uygundur (Sen, 2010, s. 60-62).

\section{Adam Smith Sorunu (Das Adam Smith Problem)}

Sen'in Smith yorumunun daha iyi anlaşılması için bu tartışmayla doğrudan ilintili olan Adam Smith sorununun ele alınması yerinde olacaktır. Adam Smith sorunu, 19. yüzyılın ikinci yarısında bir grup Alman entelektüelin Smith'in çalışmalarını ahlaki ve felsefi yönlerden anlamaya çalışmasını ifade etmektedir. Nihayetinde bu tartışma Smith'in iki eseri (Ahlaki Duygular Kuramı ve Ulusların Zenginliği) arasında özsel bir ayrıma odaklanmaktadır.

Smith'in ilk çalışması Ahlaki Duygular Kuramı (1759) “sempati” kavramı üzerinde dururken sonraki çalışması Ulusların Zenginliği (1776) "kişisel çıkar” kavramı üzerinde durmaktadır. Bu tartışmaya göre Smith'in iki eseri arasında felsefi bir kopukluk vardır. Smith, bu eserlerinde insan doğasının iki çelişik yönünü göstermektedir. Sempati ve kişisel çıkar arasındaki zıtlık Adam Smith sorunu tartışmasının özüdür (Teichgraeber, 1981; Wilson ve Dixon, 2006). Bu durum Sen'in Smith yorumuyla paralellik arz etmektedir.

Bu uzun tartışma birbirinden farklı dört grup entelektüel tarafından ele alınmıştır. Birinci gruptaki entelektüeller, Adam Smith sorununu kabul etmektedirler. Bu entelektüellere göre Smith'in iki çalışmasında antropolojik varsayımlar açısından çelişkili bir durum vardır ve bu durum Smith'in entelektüel gelişimiyle ilgilidir. Smith, Fransa'ya yaptığı gezi sonrasında antropolojik görüşlerini değiştirmiştir. Bruno Hildebrand, Carl G. A. Knies, Witold von Skarzynski ve Lujo Bretano gibi 19. yüzyılın ikinci yarısındaki çoğu felsefeci, iktisatçı, sosyal bilimci ve tarihçi Smith'in hocası Francis Hutcheson ile arkadaşı David Hume'dan etkilendiğini iddia etmişlerdir. Söz konusu yazarlara göre Smith, Hutcheson'dan cömertlik ve Hume'dan ise sempati kavramını ${ }^{3}$ almıştır. Bu iki kavram temelinde Smith, ahlak felsefesi- 
ni geliştirmiştir. Ahlaki Duygular Kuramı'nı Fransa gezisinden önce yazdığı için bu eser, insan davranışlarını sempati kavramı temelinde anlamaya çalışırken; Fransa gezisi sonrası Smith, Fransız materyalist yazarlar Helvetius ve Holbach'in etkisiyle yazdığı Ulusların Zenginliği'nde insan davranışlarını kişisel çıkar kavramı temelinde açıklamaya çalışmıştır. Bu grup entelektüellerin Adam Smith sorunu yorumlarına "Fransız bağlantılı teori” denmektedir. Bu görüşe göre Smith’in düşüncelerinde bu çelişkinin varlığı biyografiktir (Göçmen, 2007, s. 5-6).

İkinci gruptaki entelektüeller, Adam Smith sorununu kabul etmekle beraber bunda herhangi bir problem görmemektedirler. Smith'in insan davranışlarındaki antropolojik yaklaşımında bir çelişki bulunmaktadır. Fakat burada herhangi bir sorun yoktur. Çünkü etik ve iktisat iki ayrı alandır; her alanın kendine has ilkeleri ve kuralları mevcuttur. Ahlaki Duygular Kuramı etik alanla ilgiliyken Ulusların Zenginliği ekonomik alanla ilgilidir. Aslında bir çelişki gibi görünen bu durum, Smith'in çalışmaları bütünlük içinde okunduğunda ortadan kalkacaktır. Bu grubun yorumu, "dualistik doğrulamacı yaklaşımdır." Bu yaklaşım büyük oranda Kantçı düalizmden etkilenmiştir (Yılmaz, 2010, s. 77).

Üçüncü gruptaki entelektüeller, savunmacı bir şekilde, Adam Smith sorununu reddetmektedirler. Onlara göre bu sorun sahtedir. Bu yorumlayıc1lara göre Smith'in terminolojisi iki eser arasında bir çelişki göstermez. Smith'in çalışmalarında herhangi bir düalizm yoktur. Smith geliştirmiş olduğu terminoloji ile kendi dönemini tasvir etmektedir. Bu savunmacı yorumun en büyük zaafı, Smith'in Ulusların Zenginliği’nde kullandığı teknik iktisadi terimleri hiçbir şekilde etik ile ilişkilendirmemesini açıklamamasıdır.

Dördüncü grup entelektüeller ise tarihsel bir yaklaşım ile Adam Smith sorununu anlamaya çalışmışlardır. Bu gruba göre Adam Smith sorunu hem sahte bir sorundur hem de değildir. Sorun Smith'in sorunu değil, gelişmekte olan ticari toplumun sorunudur. Ticari toplumla geleneksel değer ve kurumlara dayalı yapı arasındaki gerilim, kaçınılmaz olarak Smith'in düşüncesinde karşılığını bulmuştur. Smith hem etiğin varlığını koruduğu hem de ticari toplumun savunuculuğunun yapılabileceği bir yapı peşindedir. Dolayısıyla Smith'in çalışmalarına yansıyan bu çelişkinin tarihsel yaklaşımla ele alındığında dönemin ruhuyla ilgili olduğu anlaşılacaktır (Göçmen, 2007, s. 5-17; Y1lmaz, 2010, s. 77-78).

Aslında Smith, yalnızca bir iktisatçı veya yalnızca bir ahlakçı olarak değil de, modernliğin ilk büyük düşünürlerinden biri olarak ele alınırsa yaklaşımının kendi içerisinde kavramsal bir sorun taşımadığı, sorunun kapitalizmin tarihsel gelişiminden kaynaklandığı görülecektir. Gelişen ticari toplum kaçınılmaz bir toplumsal gerilim ortaya çıkarmıştır: Bir tarafta değerler ve diğer tarafta iktisadi çıkarlar. Smith 
bir yandan merkantilist yapıya karşı serbest ticaret toplumunun övgüsünü yaparken, diğer yandan onun içsel eleştirisini geliştirme çabası içerisindedir. Smith'in teorik çabası, ister politik iktisadın isterse de daha genel bir toplumsal teori inşası şeklinde olsun, İskoç Aydınlanması'nın iç gerilimlerini bünyesinde taşımaktadır. Yaklaşımındaki kavramsal sorunun kökleri İskoç geleneğindeki yurttaşlık geleneği ile doğal hukuk geleneğinin birlikte var olmasından kaynaklanmaktadır (Yılmaz, 2010, s. 75-78).

Sen, bu tartışmaya atıfla ahlak felsefesi teorisyeni ve öncü iktisatçı olarak Smith'in ağır bir şizofren vakası olmadığını belirtmektedir (Sen, 2003, s. 33). Bununla beraber Sen, bu tartışmaya doğrudan müdahil olmamaktadır. Sen'in bu tartışmadan haberdar olduğu açıktır (Sen, 1986, s. 29). Fakat İskoç Aydınlanma geleneği etrafında Smith'in düşüncelerini açılamak istemediği de görülmektedir. Sen daha çok, Smith'i bir bütünlük içerisinde 18. yüzyıl bağlamından günümüze taşımak istemektedir.

Bu bağlamda Smith'in düşüncelerinin bir bütünlük arz ettiği söylenebilir. Yaşadığ1 dönem itibariyle Smith'in iktisadi düşüncesini politik düşünceleriyle bağlantılı anlamak gerekmektedir. Smith'in iktisat anlayışı; hukuk, felsefe ve ahlak görüşleriyle bağlantılı ve birbirlerini bütünleyici tarzdadır. İnsan davranışlarının ilkeleri, iş bölümü ve yetenekler üzerine yazıları bir plan dâhilinde ele alınmıştır (Rothschild ve Sen, 2006, s. 319; Samuels, 1977, s. 8). Bu nedenle Smith'in düşüncelerinin merkezinde sadece iktisat yoktur. İktisatla beraber politika, felsefe ve hukuk vardır. Şüphesiz Smith gerçekleşmekte olan kapitalizmin sosyolojik analizini yapmaktadır. Bundan dolayı iktisadın modern yaşam içerisindeki belirleyici rolünü görmezden gelmesi beklenmemelidir. Fakat düşüncelerini ifade ederken iktisadın bu merkezî konumunun yanında insan davranışlarının genel kurallarını, hukuku ve ahlakı da göz ardı etmemiştir. Dolayısıyla Smith'in yazılarında iktisat (gelişen ticari toplum), fotoğrafın tamamını değil, bir bölümünü oluşturmaktadır. Bundan dolayı Sen'in geliştirdiği Smith yorumu, bu farkındalığı belirtmesi açısından yerindedir.

Sen'in Smith'le ilgili yorumlarında bazı tespitler göze çarpmaktadır. Bu tespitlerden birincisi, Smith'in kendi düşünsel aurası bağlamında ele alınmamış olmasıdır. Bu bağlamda Smith, modern piyasa tartışmalarının merkezine oturtularak asli mecrasından uzaklaştırllmış ve düşüncesinin bütünlüğü ihmal edilerek çağdaş ana akım iktisadın teorik malzemesi olarak kullanılmıştır. Şayet Smith etrafındaki bu yanlış algılama giderilirse hem Smith doğru değerlendirilecek hem de çağdaş iktisadi düşünce daraltılmış yönlerinden kurtulacaktır.

İkincisi, Sen, Smith yorumuyla neoklasik iktisadın gerçek-değer ayrımını reddetmektedir. Sen, neoklasik iktisada mantıksal pozitivistler tarafından taşınan 
"anlaml”" cümle ve "değerlerin” sübjektifliği gibi ayrımları, Smith’in etik yaklaşımını savunarak geçersiz kılmaya çalışmaktadır. Sen, Smith üzerinden iktisada "değerleri” taşımaktadır (Walsh, 2000, s. 6-7).

Üçüncüsü, Smith, 18. yüzyılda hâkim görüş olan merkantilizm ve kısıtlayıc1 piyasa karşısında serbest ticaret ve bireysel özgürlüğü savunurken; Sen, ortodoks iktisatta hâkim görüş olan refahçılık ve insan refahının iktisadi içerikle açıklandığı geleneksel refah iktisadına pozitif özgürlük nosyonu olan yapabilirliklerle meydan okumuştur. Smith'in gereklilikler analizi ile Sen'in yapabilirlikler yaklaşımı arasında açık bağlantılar vardır (Boz, 2012, s. 75). Yapabilirlik yaklaşımının temel iddiası; bir kişinin ne kadar iyi bir durumda olduğunu anlamak için, kişinin ne tarz bir yaşam sürdüğü, oluş (beings) ve yapışlar (doings) konusunda neleri başardığına bakmak gerektiği şeklindedir. Dolayısıyla, yapabilirlik yaklaşımı, bireysel refah (well-being) ve toplumsal düzenlemelerin değerlendirilmesi, toplumdaki değişimlere yönelik önerilerin ve politikaların tasarımı için geniş bir normatif çerçevedir (Boz, 2009, s. 9; Walsh, 2000, s. 13).

Dördüncüsü, Sen'e göre, refah yegâne değer değildir ve fayda, refahı tatmin edici biçimde temsil etmez. Eylem kapasitesi kişinin refahının bir parçasıdır. Ama bu kapasite, ortaya çıkardığı “ürüne” indirgenemez. Bu aşamada Sen'in yaklaşımında, Rawls'dan çok Marx’a yakın duran, tözcü bir özgürlük felsefesinin izleri ortaya çıkmaktadır. Özgürlük sayesinde gerçekleşenlerden ziyade, özgürlüğü elinde tutmanın kendisinin bireyin yararını daha iyi temsil ettiği fikri, Sen’in yaklaşımının ana eksenini oluşturur: "Özgürlük, sadece bazı şeyleri gerçekleştirmek olanağı verdiği için değil, ulaşılan varlık durumunun değerinin ötesinde, sadece kendi önemi nedeniyle kıymetli addedilebilir”. Dolayısıyla özgürlük için sadece biçimsel özgürlükler, kaynaklar, gelir yeterli değildir. Temel insani faaliyet olanaklarını kullanmak ve geliştirmek kapasitesi esastır (İnsel, 2000, s. 16; Sen, 2003, s. 55).

Beşincisi, Sen, yapabilirlik yaklaşımını geliştirdiği Özgürlükle Kalkınma ile çağdaş politik sorunları tartıştığı Adalet İdeası adlı eserlerinin güçlü bir şekilde Smithyen karakter taşıdığını ifade etmektedir (Sen, 2004, s. 346; Sen, 2009a). Bundan dolayı Sen, Smith'i bugüne taşıma çabasıyla klasik iktisadın günümüzdeki modern temsilcisi olarak görülebilir.

\section{Sonuç}

Kapitalizmin ortaya çıkışı her hangi bir ideolojinin başka bir ideoloji karşısındaki zaferiyle açıklanmayacak kadar karışık ve dolambaçlı bir öyküye sahiptir. Bernand Mandeville, bu durumu, Arılar Masalı'nın çeşitli kısımlarında "bireysel günahları 
toplumsal faydaya" dönüştürmekten bahsederek ifade etmektedir. Adam Smith ise "tutku" ve "günah" gibi terimlerin yerine "avantaj" ve "çıkar" gibi daha renksiz terimleri kullanarak Mandeville'in paradoksunun keskinliğini yumuşatmıştır. Bu düşünce, 19. yüzyıl liberalizminin önemli bir dayanağı ve iktisat teorisinin ana akımı olarak gelişme göstermiştir (Hirschman, 2008, s. 34-39).

Bununla beraber hakkında en fazla spekülasyon yapılan iktisatçıların başında gelen Smith, bir yandan merkantilist yapıya karşı serbest ticaret toplumunun övgüsünü yaparken, diğer yandan onun içsel eleştirisini geliştirme peşindedir (Yılmaz, 2010). Hükümetin bireyleri sınırlayan uygulamalarını minimize etmeye çalışmıştır. Bununla beraber ekonomik büyümenin sosyal, psikolojik maliyetleri ve etik, Smith'in ilgilendiği en önemli konulardır. Bu nedenle Smith, 18. yüzyıl politik bağlamı içerisinde okunmalıdır. Smith, 19. yüzyıl veya 20. yüzyıl politik ikliminde bir liberal düşünür olarak okunursa şüphesiz Smith'in bütünlükçü düşüncesi tam olarak anlaşılmayacaktır (Winch, 1978, s. 2; Skinner, 1988, s. 8). Aksine Smith, bir sosyal bilimci olarak kendi döneminin koşulları göz önüne alınarak incelenirse, Smith'in yazılarının günümüzün birçok tartışmasını önceden haber verdiği görülecektir (Özveren, 2010, s. 52).

Amartya Sen de Adam Smith'in düşüncelerini, kapitalizmin ortaya çıkışı bağlamında ve Smith'i bir sosyal bilimci olarak analiz etmeye çalışmıştır. Bu nedenle Sen'in Smith yorumu, dikkate değer bir farkındalık oluşturmaktadır. Sen'e göre Smith, günümüzün sorunlarını önceden haber veren en öngörülü filozofların başında gelmektedir.

Bu çalışmada Adam Smith'in Amartya Sen üzerindeki düşünsel etkisi ele alınmıştır. Bu etki, gelişen ticari toplumun ve iktisat disiplininin felsefi temelli kavranışına fırsat sunmaktadır. Bundan dolayı Amartya Sen'in Adam Smith yorumu sadece çağdaş bir iktisatçının klasik bir iktisatçıyı değerlendirmesi olarak görülmemelidir. Bu girişim, Smith gibi Batı düşüncesine yön vermiş çok yönlü bir düşünürün, Sen gibi çağdaş dönemde sosyal bilimlere yön vermiş bir başka düşünür tarafından yorumlanmasıdır. Çünkü Smith, sadece modern iktisadın kurucusu olarak kalmamakta aynı zamanda İskoç Aydınlanmasının kurucu isimlerinden ve gerçekleşmekte olan kapitalizmin en öngörülü kuramcılarından biridir. Sen ise yirminci yüzyılın ikinci yarısında iktisat ve felsefe gibi iki disiplin arasındaki derin ayrılığı gidermeye çalışmıştır. Aynı zamanda Amerikan haklar kuramı tartışmalarını sosyal adalet bağlamında etkilemiş ve refah iktisadına yapmış olduğu katkılarla Nobel İktisat ödülü almış önemli bir isimdir. Bu nedenlerden ötürü Sen'in Smith değerlendirmesi, iktisat disiplininin kendi içerisindeki bir tartışmadan ziyade disiplinler arası bir yaklaşım geliştirme denemesidir. 
Sen'e göre Smith modern iktisat teorisinde vülgarize edilmiştir. Bu durum hem Smith gibi çok yönlü bir düşünürü hem de modern iktisat teorisini sınırlamıştır. Smith'in doğru anlaşılması, hem çağdaş sosyal adalet düşüncesinin hem de modern iktisadın zenginleşmesine imkân sağlayacaktır.

Sen'in Smith okumasının biri disipliner diğeri de politik olmak üzere iki iması bulunmaktadır. Smith'e dayanılarak geliştirilen disipliner ima, Sen'in iktisat disiplinini dar bir çerçevenin dişında okuma ve geliştirme isteğidir. Bir başka deyişle Sen'in Smith okuması, modern iktisada etik kuramı tekrar yerleştirme girişimidir. Dolayısıyla Sen, iktisadı felsefeyle anlamaya gayret etmektir. Politik ima ise iktisadi liberalizme yönelik örtük bir eleştiridir. Bu eleştiri, insan davranışlarının sadece kişisel çıkara dayalı açıklanmasının piyasa ekonomisi içinde almış olduğu pozisyondan duymuş olduğu memnuniyetsizliktir. Fakat bu eleştiri, kapitalizmin köktenci bir biçimde sorgulanmasının yapılması anlamına gelmemektedir. Ahmet İnsel'in (2000, s. 20) yerinde tespitiyle Sen, iktisadi analiz yaklaşımını, yöntemsel bireycilik, etik bireycilik ve siyasal liberalizmi birleştirerek başarmaya çalışmaktadır. Ortodoks olmayan araştırma programını, standart bir metodolojiyle yürütebilmektedir. Bu açıdan Sen, hem eleştirel hem de "uygun" bir iktisat yaklaşımının günümüzdeki önde gelen temsilcisidir. Sonuç olarak Sen'in yaklaşımının asıl önemli yanı, eleştirel olması değil, bireysel çıkar normuna bariz biçimde uymayan kuramsal araçları Smith'e atıf yaparak geliştirip, iktisat kuramının merkezine "değerleri" yerleştirebilmesidir. Bu nedenle Sen'in yaklaşımında sosyal teorinin iki karşıt kutbu olarak görülen Smith ve Marx rahat bir şekilde yer almaktadır. Sen (2004, s. 356) için kapitalizm, özellikle iktisadi eşitsizlik, çevrenin korunması ve piyasa dışında işleyen farklı türlerin işbirliği ihtiyacı konusunda kısıtları olmakla beraber, piyasa mekanizmasının ve ilgili kurumların başarılı kullanımı için gerekli olan vizyonu ve güveni sağlayan bir etik sistem aracılığıyla etkin biçimde işlemektedir. Görüldüğü üzere Sen'in Smith yorumu, kapitalizmi köklü bir şekilde sorgulamaktan uzaktır. Bu yorum, daha çok kapitalizmi etik zemine çekme isteğinden doğmaktadır. 

Amartya Sen's Reading of Adam Smith

\author{
Adem Levent
}

\title{
Introduction
}

Adam Smith, the most significant theorist of the market economy, is known as the founder of the modern economy. However, some social democratic academics have recently become interested in his thought (Smith, 2013a, p. 784). For this reason, Smith remains not only the founder of modern economics, but is also cited by liberal and Marxist researches. All of these approaches are derived from economists who have adopted different views of the market economy. Thus, Smith has been become an object of an ideological debate depending upon the economist's political preferences. The literature on him that, has developed within the field of economics, is both diverse and controversial. While he is the main point in this literature, he is also the "founding" figure of economics and thus subject to various interpretations (Yilmaz, 2010, p. 65).

Amartya Sen, winner of the 1998 Nobel Prize in Economic Science, has drawn some attention with his research on this seminal figure. This paper explains how the debates of political economics, starting with Smith, were transformed into contemporary economic problems even if the discipline of the economy has not been fully formalized. This work explains this transformation based on Sen's new research.

\section{Adam Smith, Self-Interest and, Prudential Behavior}

According to Sen, contemporary economic theory has -and continues to- misinterpret Smith's thought regarding the rationality of human behavior, the market economy and the role of the state's role in the economy (Sen, 2011). Sen posits 
that although the "Smithian" view is based upon the idea that behavior grounded in self-interest is valid in all situations and provides efficiency itself, there is not enough evidence that Smith himself believed in these ideas. The concept of "self-control," which Smith received from Stoic philosophy, is by no means identical with "self-interest" (Sen, 2003, pp. 28-30). Other studies have dealt with the simplification of Smith's ideas in contemporary economic theory, among them those by Karl Polanyi and Giovanni Arrighi.

\section{Adam Smith and Contemporary Political Thought}

According to Sen, Smith's thoughts give a clue to how a society will be established and how justice ideas will be achieved. This situation is contemporarily a subject of social justice (Sen, 2009b). Sen writes that despite the long history of the idea of social justice, this idea was analyzed more systematically during the Enlightenment in terms of the changing political, social and economic environments of the 18th and 19th centuries. From that time on, two basic methodologies to social justice thought were considered. The first one, that of the social contract, which began with the work of Thomas Hobbes (1588-1679) and continued with the writings of John Locke (1632-1704), Jean-Jacques Rousseau (1712-78) and Immanuel Kant (1724-1804); this understanding, which suggests an institutional arrangement for society known as "transcendental institutionalism" has two notable features: (1) it seeks a perfect definition of justice, rather than comparing justice and injustice, and thus focuses on comparing communities, and (2) it concentrates on institutional arrangements. This approach does not address current problems of societies. The nature of the society is tried to be defined by its non-institutional characteristics as much as it is institutional.

The second approach to social justice is the tradition of social realization, which is comparative in nature and thus compares and contrast current institutions, current behavior and other actual effects with each other in an attempt to achieve social justice. According to Sen, Adam Smith is the strongest representative of many other innovative thinkers that can be included in this tradition, among them. Marquis de Condorcet (1743-94), Jeremy Bentham (1748-1832), Mary Wollstonecraft (1759-97), Karl Marx (1818-83) and John Stuart Mill (1806-73). All of them, despite their differences held one point in common: justice can be realized. Unlike the adherents of transcendental institutionalism, their main goal is not define justice in a perfect way, but to remove the injustice, slavery, poverty, exploitation and the abuse of women so that justice can occur (Sen, 2010, pp. 57-58, Sen, 2013, p. 588). 


\section{Das Adam Smith Problem}

In order to better understand Sen's interpretation, I will use "Das Smith problem" which is directly related to this argument. This "problem" appeared during the second half of the 19th century, when a group of German intellectuals expressed Smith's work in terms of its moral and philosophical aspects. Ultimately, this discussion addresses on an essential separation between Smith's The Theory of Moral Sentiments (1759) and his An Inquiry into the Nature and Causes of the Wealth of Nations (1776). The first study examines "sympathy," and the second one ponders "self-interest." According to this argument there is a philosophical disconnect between these two works, because sympathy and self-interest are two contradictory directions of human nature. This is the essence of the "Adam Smith problem" (Teichgraeber, 1981; Wilson and Dixon, 2006) and is consistent with Sen's comment.

In fact, considering Smith one of the first great thinkers of modernity, instead of just an economist or a moralist, one sees that this "problem" is rooted in the historical development of the "problem" of capitalism. In other words, his approach is not a conceptual problem in and of itself because an emerging commercial society creates an inevitable social tension between values and economic interest. Smith praises the free-trade society against the mercantilist structure while trying to develop an internal criticism of the free-trade society. Smith's theoretical attempt to construct a more general social theory, whether or not it is political economics, carries the internal tensions of the Scottish Enlightenment. The roots of the noted conceptual problem in his approach is due to the coexistence of the tradition of citizenship and of natural law in the Scottish tradition (Yllmaz, 2010, pp. 75-78).

Sen refers to this argument as a moral philosopher- theoretician and a pioneer economist that Smith is not a severe schizophrenic (Sen, 2003, p. 33). Although, Sen is not directly involved in this debate, he is clearly aware of it (Sen, 1986, p. 29). But it appears that Sen does not want to explain Smith's thoughts in terms of the Scottish Enlightenment tradition but rather wants Smith to be placed within the context of the 18th century as a whole.

Some of Sen's points are striking. The first one is that Smith is not addressed within the context of his intellectual era for he has been removed from it and made a part of modern market debates. In other words, the totality of his thought has been neglected and that part of it that has proven to be "useful" has been used as the theoretical material of contemporary mainstream economics. If this misunderstanding is resolved, Smith will be judged correctly and contemporary economic thought will be rescued from its narrowness. 
Second, Sen rejects the real-value distinction of neoclassical economics by attempting to override the distinctions made by logical positivists in neoclassical economics (e.g. the "meaningful" sentence and the subjectivity of "values") in order to defend Smith's ethical approach. Thus, he is carrying "values" on the economy through Smith (Walsh, 2000, pp. 6-7).

The third contention is that defended free trade and individual freedom in the face of mercantilism and the restrictive market (the dominant view during the 18th century). Sen challenges the feats of welfare (the prevailing opinion in orthodox economics) and the feasibility of positive freedom to the traditional welfare economy (explained by the economic content of human well-being). There is a clear connection between Smith's analysis of requirements and Sen's approach to feasibility (Boz, 2012, p. 75). The basic assertion of the feasibility approach is to understand when a person is in a good situation, what kind of life one is going through, what one has to achieve and what one has to do.

Fourth, according to Sen, welfare is not the only value, and benefit does not represent satisfactory welfare. The capacity for action is part of one's well-being; however, this capacity cannot be reduced to the "product" that it reveals. At this stage, Sen's approach reveals traces of a philosophy of freedom that is more like that of Karl Marx than Rawls (1921-2002) (İnsel, 2000, p.16; Sen, 2003, p. 55).

Fifth, Sen stresses the Smithian character in two of his own books: The Idea of Justice (Canada: Allen Lane: 2009), which discusses contemporary political issues, and Development as Freedom (New York: Oxford University Press, 1999), in which he developed a feasibility approach (Sen, 2004, p. 346; Sen, 2009a). Therefore, Sen can be seen as the modern representative of classical economics today due to his effort to bring the totality of Smith's economic thought into the 21st century to this day.

\section{Conclusion}

The emergence of capitalism has a complex and devious story that cannot be explained as one ideology's victory over another. Bernard Mandeville (1670-1733) expresses this by referring to the "turning of individual sins into social benefits" in various parts of his "The Fable of the Bees." Also known as Private Vices, Public Benefits, this book first appeared in 1714. Adam Smith softened the sharpness of Mandeville's paradox by using soft terms such as "advantage" and "interest," instead of "passion" and "sin." This idea has developed as a mainstay of 19th-century liberalism and as the main stream of economic theory (Hirschman, 2008, pp. 34-39). 
Sen also tried to analyze Smith's thoughts within the context of the emergence of capitalism and Smith as a social scientist. For this reason, he interprets Smith as a very aware person and as one of the most predictive philosophers who anticipated present day problems.

He argues that the simplification of Smith's idea in modern economic theory limits both a well-rounded thinker and modern economic theory, and that a more accurate understanding will enrich both contemporary social justice efforts and modern economics.

Sen's reading of Smith has two connotations: as discipline and as politics. The discipline connotation, which based upon Smith, is Sen's reading and request of economic discipline transcend its current narrow framework. In other words, his reading of Smith is an attempt to relocate ethical theory in modern economics by trying to understand the economy via philosophy. The political connotation is the implicit criticism of economic liberalism, namely, dissatisfaction with the position that human behavior is based solely upon self-interest in amarket economy. But this criticism does not mean that he questions capitalism in a fundamental way. According to Ahmet İnsel (2000, p. 20), Sen is trying to formulate an economic analysis by combining methodological individualism, ethical individualism and political liberalism. The non-orthodox research program can be carried out with a standard methodology. In this respect, Sen is today's leading representative of both a critical and a "suitable" economic approach.

\section{Kaynakça | References}

Arrighi, G. (2009). Adam Smith Pekin'de. (İ. Yıldız, Çev.) İstanbul: Yordam Kitap.

Blaug, M. (1999). Economic theory in retrospect. Cambridge: Cambridge University Press.

Boz, Ç. (2009). Amartya Sen'in yetkinlik yaklaşımı: teori ve uygulama (Doktora tezi, Yıldız Teknik Üniversitesi, Sosyal Bilimler Enstitüsü, İstanbul). http://tez2.yok.gov.tr/ adresinden edinilmiştir.

Boz, Ç. (2012). Adam Smith ve Amartya Sen, Gazi Üniversitesi İktisadi ve İdari Bilimler Fakültesi Dergisi. 14 (3), 71-96. Eiffe, F. F. (2008). Amartya Sen reading Adam Smith, History of Economics Review. 1-23.

Fine, B. ve Milonakis, D. (2014). İktisat emperyalizminden acayip iktisada. (E. Kırmızıaltın ve H. Bilir, Çev.). Ankara: Heretik Yayıncilik.

Göçmen, D. (2007). The Adam Smith problem human nature and society in the theory of moral sentiments and the wealth of nations. London: Tauris Academic Studies.

Hirschman, A. O. (2008). Tutkular ve çıkarlar. (B. Cezar, Çev.) İstanbul: Metis Yayınları.

Hirshleifer, J. (1985). The Expanding Domain of Economics. The American Economic Review, 75 (6), 53-68.

Holthoon, F. L. V. (1993). Adam Smith and David Hume: with Sympathy. Utilitas, 5 (1), 35-48.

Hutchison, T. (1994). The uses and abuses of economics contentious essays on history and method. London: Routledge.

İnsel, A. (2000). Özgürlük Etiği Karşısında İktisat Kuramı: Amartya Sen'in Etik İktisat Önerisi. Toplum ve Bilim, 86 (Güz), 7-21. 
Khalil, E. L. (2002). Is Adam Smith Liberal? Journal of Institutional and Theoretical Economics, 158 (4), 664-694.

Klamer, A. (1989). A Conversation with Amartya Sen. Journal of Economic Perspectives, 3 (1), 135-150.

Lazear, E. P. (2000). Economic Imperialism. The Quarterly Journal of Economics, 115 (1), 99-146.

Meda, D. (2012). Emek kaybolma yolunda bir değer mi?. (I. Ergüden, Çev.) İstanbul: İletişim Yayınları.

Özveren, E. (2010). Bir Sosyal Bilimci Olarak Adam Smith’in Uzak Görüşlülüğü. M. Kara ve N. E. Aydınonat (Ed.), Görünmez Adam Smith içinde (s. 19-52). İstanbul: İletişim Yayınları.

Polanyi, K. (2000). Büyük dönüşüm çağımızın sosyal ve ekonomik kökenleri. (A. Buğra, Çev.) İstanbul: İletişim Yayınları.

Rawls, J. (2005). A theory of justice. Cambridge: The Belknap Press.

Rawls, J. (2007). Siyasal liberalizm. (M. F. Bilgin, Çev.) İstanbul: İstanbul Bilgi Üniversitesi Yayınları.

Rothschild, E. and Sen, A. (2006). Adam Smith's Economics. Knud Haakonssen (Ed.), The Cambridge Companion to Adam Smith içinde (s. 319-366). Cambridge: Cambridge University Press.

Samuels, W. J. (1977). The Political Economy of Adam Smith. Ethics, 87 (3), 189-207.

Schumpeter, J. A. (1986). History of economic analysis. London: Routledge.

Sen, A. (1977). Rational Fools: A Critique of the Behavioral Foundations of Economic Theory. Philosophy \& Public Affairs, 6 (4), 317-344.

Sen, A. (1986). Adam Smith's Prudence, S. Lall and F. Stewart (Ed.), Theory and Reality in Development içinde (s. 2837). London: Macmillan Press.

Sen, A. (2003). Etik ve ekonomi. (A. Süha, Çev.) İstanbul: Doğan Kitap.

Sen, A. (2004). Özgürlükle kalkınma. (Y. Alogan, Çev.) İstanbul: Ayrıntı Yayınları.

Sen, A. (2009a). The idea of justice. Cambridge: Belknap Press.

Sen, A. (2009b). Capitalism Beyond the Crisis. The New York Review of Books, 56 (5), 1-7.

Sen, A. (2010). Adam Smith and The Comtemporary World. Erasmus Journal for Philosophy and Economics, 3 (1), 50-67.

Sen, A. (2011). Uses and Abuses of Adam Smith. History of Political Economy, 43 (2), 257-271.

Sen, A. (2013). The Comtemporary Relevance of Adam Smith. C. J. Berry, M. P. Paganelli ve C. Smith (Ed.), The Oxford Hand Book of Adam Smith içinde (s. 581-591). Oxford: Oxford University Press.

Skiner, A. (1988). Adam Smith and Economic Liberalism. The David Hume Institute Hume Occasional Paper, 9, 1-31.

Skousen, M. (2003). Modern iktisadın inşası. (M. Acar, E. Erdem ve M. Toprak, Çev.) Ankara: Liberte Yayınları.

Smith, C. (2013a). Adam Smith: Left or Right? Political Studies, 61, 784-798.

Smith, A. (2013b). Milletlerin zenginliği. (H. Derin, Çev.) İstanbul: İş Bankası Kültür Yayınları.

Stigler, G. (1971). Smith's Travel on The Ship of State. History of Political Economy, 3, 265-277.

Teichgraeber, R. (1981). Rethinking Das Adam Smith Problem. Journal of British Studies, 20 (2), 106-123.

Viner, J. (1927). Adam Smith and Laissez Faire. Journal of Political Economy, 35 (2), 198-232.

Walsh, V. (2000). Smith After Sen. Review of Political Economy, 12 (1), 5-25.

Winch, D. (1978). Adam Smith's politics an essay in historiographic revision. Cambridge: Cambridge University Press.

Wilson, D., and Dixon, W. (2004). Das Adam Smith problem: A critical realist perspective. www.brill.nl. adresinden alınmıştır.

Yılmaz, F. (2010). Adam Smith ve İskoç Aydınlanması, M. Kara ve N. E. Aydınonat (Ed.), Görünmez Adam Smith içinde (s. 65-85). İstanbul: İletişim Yayınları. 
